\title{
Configurações
}

Revista de sociologia

\section{Construtivismo bourdieusiano como linguagem: uma interpretação pragmática*}

Bourdieusian constructivism as a language: a pragmatic interpretation Le constructivisme bourdieusien en tant que langage: Une interprétation pragmatique

\section{Márcio Sá}

\section{OpenEdition}

\section{Journals}

\section{Edição electrónica}

URL: http://journals.openedition.org/configuracoes/2881

DOI: 10.4000/configuracoes.2881

ISSN: 2182-7419

\section{Editora}

Centro de Investigação em Ciências Sociais

\section{Edição impressa}

Data de publição: 18 Dezembro 2015

Paginação: 115-128

ISBN: 1646-5075

ISSN: 1646-5075

\section{Refêrencia eletrónica}

Márcio Sá, « Construtivismo bourdieusiano como linguagem: uma interpretação pragmática* », Configurações [Online], 16 | 2015, posto online no dia 29 dezembro 2015, consultado o 19 abril 2019. URL : http://journals.openedition.org/configuracoes/2881; DOI : 10.4000/configuracoes.2881 
Sá, Marcio - Construtivismo bourdieusiano como linguagem: uma interpretação pragmática. Configurações, vol. 16, 2015, pp. 115-128

\title{
Construtivismo bourdieusiano como linguagem: uma interpretação pragmática*
}

\author{
MARCIO SÁ**
}

Universidade Federal de Pernambuco

\begin{abstract}
Resumo
Pierre Bourdieu consagrou lugar privilegiado à construção do objeto em seu modus operandi. Este não surgiu antes nem somente depois do contato com o campo, mas sim enquanto suas pesquisas eram feitas e aperfeiçoadas. Neste ensaio são resgatados aspectos centrais da evolução de sua epistemologia relacionados à construção do objeto de pesquisa e uma visão de sua teoria como uma prática social como as demais, para então chegar ao seu principal objetivo: expor uma interpretação pragmática do construtivismo bourdieusiano como linguagem a partir do segundo Wittgenstein. Ao final são apresentadas algumas considerações sobre e para a prática do investigador social.
\end{abstract}

Palavras-chave: epistemologia; construtivismo; linguagem; Bourdieu; Wittgenstein.

\begin{abstract}
Bourdieusian constructivism as a language: a pragmatic interpretation

Pierre Bourdieu devoted a privileged place to the construction of the object in his modus operandi. This did not arise before nor after getting in contact with the field, but while his research was being made and refined. In this essay, core aspects of the evolution of his epistemology, related to the construction of the research object, and a vision of his theory as a social practice like others are retrieved. It then proceeds to reach its main goal: to expose a pragmatic interpretation, from the second Wittgenstein, of

\footnotetext{
* Este trabalho é uma síntese de aspectos teórico-epistemológicos tratados em Sá (2015). Registro meus agradecimentos ao Professor Pedro Lincoln C. L. de Mattos (UFPE-Brasil), não somente pela introdução em leituras da filosofia pragmática da linguagem, mas também pelas conversas por meio das quais pude chegar a esta interpretação. Também agradeço ao Prof. Virgílio Borges Pereira, tanto pela leitura atenta da sinopse deste artigo quanto pela sugestão de sua submissão para publicação em Configurações.

** Doutorado em Sociologia, Universidade Federal de Pernambuco. Email: marciodesa@gmail.com.
} 
Bourdieusian constructivism as a language. Finally, some considerations are presented about and addressed to the social researcher's practice.

Keywords: epistemology; constructivism; language; Bourdieu; Wittgenstein.

\section{Résumé}

Le constructivisme bourdieusien en tant que langage: Une interprétation pragmatique Pierre Bourdieu a consacré dans son modus operandi une place privilégiée à la construction de l'objet. Celui-ci ne surgit pas avant ou uniquement après le contact avec le terrain, mais tout au long du déroulement et du perfectionnement de la recherche. Dans cet essai, nous avons repris des aspects fondamentaux de l'évolution de son épistémologie liés à la construction de l'objet de recherche, ainsi qu'une vision de sa théorie en tant que pratique sociale comme les autres, pour ensuite atteindre son principal objectif : présenter une interprétation pragmatique du constructivisme bourdieusien comme un langage à partir du second Wittgenstein. A la fin, quelques considérations à propos de et pour la pratique du chercheur en sciences sociales sont présentées.

Mots-clés: épistémologie; constructivisme; langage; Bourdieu; Wittgenstein.

"The fundamental scientific act is the construction of the object" (Bourdieu)

"Pronunciar uma palavra é como tocar uma tecla do piano da imaginação" (Wittgenstein)

\section{Introdução}

Pierre Bourdieu não seguia manuais de metodologia, mas era rigoroso no modo como pesquisava e nas operações específicas que procedia em seu ofício. Não foi à toa que consagrou lugar privilegiado à construção do objeto em sua epistemologia. Esta atividade é a pedra angular de um modo de produção científica que não surgiu antes nem somente depois do contato com o campo, mas sim enquanto as pesquisas eram feitas e aperfeiçoadas por ele próprio. Um dos seus mais proeminentes herdeiros científicos afirma ser justamente em tal modus operandi (e não no opus operatum) do seu mestre que se encontra a melhor definição de sua originalidade (Wacquant, 1992). O próprio Bourdieu (1989a: 22) explicitou o que teria de ser ensinado sobre o ofício, para ele, "essencialmente, um modus operandi, um modo de produção científico [...] cuja única maneira de o adquirir é o de ver operar praticamente ou observar o modo como este habitus científico ${ }^{1}$

1 Segundo Bourdieu (1989a: 23): “O habitus científico é uma regra feita homem ou, melhor, um modus operandi científico que funciona em estado prático segundo as normas da ciência sem ter estas normas na sua origem: é esta espécie de sentido do jogo científico que faz com que se faça o que é preciso fazer 
- é bem este o seu nome -, sem necessariamente se tornar explícito em preceitos formais, 'reage' perante opções práticas".

Considerando que o sociólogo francês consagrou à construção do objeto a condição de "ato científico fundamental", uma vez interpretado em termos pragmáticos, é possível apontar que ele criou e praticou uma linguagem sobre o mundo social. É a riqueza e abertura de tal criação que vai além da contingência das opções teórico-epistemológicas que tomou na França do século passado e torna sua obra tão inspiradora. Neste ensaio são resgatados (1) aspectos centrais da evolução de sua epistemologia relacionados à construção do objeto de pesquisa e (2) uma visão de sua teoria como uma prática social como as demais, para então chegar ao seu principal objetivo: (3) expor uma interpretação pragmática do construtivismo bourdieusiano como linguagem a partir do segundo Wittgenstein. Ao final são apresentadas breves considerações sobre e para a prática do investigador social.

\section{Epistemologia e método de construção do objeto}

\subsection{Origens das concepções epistêmicas}

Falar sobre a construção de objetos no trabalho de Bourdieu é inevitavelmente recuperar alguns aspectos centrais de sua epistemologia. O meio no qual foi formado lhe propiciou contato íntimo com a tradição epistemológica da filosofia e história das ciências francesa, e a epistemologia que toma para si está bem fincada neste território. Recuperar as concepções epistêmicas fundamentais para que ele desenvolvesse um modus operandi original, que toma a construção do objeto como ato fundamental, é observar a incontornável influência sui generis que recebeu de Gaston Bachelard, principalmente se comparado a outros autores dos quais se municiou. Enquanto se apoiava e "corrigia criticamente" clássicos, ou seja, pensava com e contra autores como Durkheim, Marx, Weber e Althusser (Vandenberghe, 1999), Bourdieu seguia Bachelard de tal modo que sua teoria social "pode ser mais bem entendida como uma tentativa de transpor, de modo sistemático, o 'racionalismo aplicado' de Bachelard do reino das ciências naturais para o domínio das ciências humanas" (Vandenberghe, 1999: 2). Além disso, as ideias de Cassirer e Saussure também devem ser destacadas numa epistemologia que muito deve "às análises proto-estruturalistas do princípio relacional nas ciências modernas (da matemática à física e à linguística) realizadas por Ernst Cassirer. De fato, o 'núcleo duro' (Lakatos) meta-científico e não-falseável do programa progressivo de pesquisa de Bourdieu é formado por uma sofisticada síntese entre o racionalismo de Bachelard e o relacionismo de Cassirer" (Vandenberghe, 1999: 3). Ou seja, tal racionalismo

no momento próprio, sem ter havido necessidade de tematizar o que havia que fazer, e menos ainda a regra que permite gerar a conduta adequada." 
aplicado bachelardiano é articulado com aspectos tomados de Cassirer, em particular a ideia de que "o real é relacional”, e de Saussure: "Embora o objeto pareça preceder o ponto de vista, Bourdieu compartilha da pressuposição construtivista de Saussure segundo a qual, na verdade, é 'o ponto de vista que cria o objeto"” (Vandenberghe, 1999: 20).

De volta ao âmbito da herança bachelardiana, um olhar mais atento para a própria estrutura e partes de O ofício de sociólogo (Bourdieu et al., 1991) aponta que "nenhum leitor de Bachelard pode deixar de reconhecer sua influência decisiva na arquitetura do texto, cujas três partes se apresentam sob rubricas cuja denominação é inconfundível: 'a ruptura', 'a construção do objeto', e 'o racionalismo aplicado'” (Baranger, 2012: 70)². Também vale a pena ter em mente que aquele livro (em coautoria) representou apenas um primeiro estágio evolutivo das concepções epistemológicas de Bourdieu, um ponto de partida no qual se encontra uma primeira apresentação extensa de suas idéias epistemológicas e metodológicas (Baranger, 2012: 59). Apesar desta importante ressalva, no livro é possível observar os "preliminares epistemológicos" presentes em lições de sua maturidade (cf. 1.3).

Dentre tais preliminares é possível destacar princípios epistemológicos como: a "ruptura epistemológica" (Bachelard, 1996), o princípio da não consciência e o princípio da primazia das relações. Quanto ao primeiro, este trecho do próprio Bachelard (1996: 18) ilustra a ideia da ruptura: "quando o espírito se apresenta à cultura científica, nunca é jovem. Aliás, é bem velho, porque tem a idade de seus preconceitos." O seu argumento é que, para fazer ciência, é preciso dar um "salto epistemológico" da sua condição prévia de vida e das visões (preconceitos) para a construção do próprio espírito científico, liberto de tais pré-noções. Já o segundo, que tem origem durkheimiana, justifica a sociologia como campo de conhecimento, afinal "a vida social tem de ser explicada não pelas concepções de seus participantes, mas por causas estruturais que escapam à sua consciência" (Vandenberghe, 1999: 16). O terceiro decorre do seu modo de pensar relacional (decorrente de Cassirer, como visto acima) que se contrapõe a uma perspectiva substancialista.

A segunda parte da obra recebeu o título "Construindo o objeto" (Bourdieu et al., 1991: 33-55). Para avançar neste sentido, seria necessário romper com a visão do senso comum - ou, nos termos de Bachelard, dar tal "salto epistemológico" - e procurar construir o "fato social" como objeto científico. Para isso seriam sociologicamente elaboradas denominações específicas para fenômenos (re)construídos como fatos sociais, denominações estas que também configurariam indicativo de uma primeira ruptura com as pré-noções da "sociologia

2 Neste texto, sempre que é citada em português uma obra referenciada em edição em língua estrangeira, a tradução foi feita por mim. A única exceção é Vandenberghe (1999), conforme indico nas referências. Em tempo, as citações de obras publicadas em Portugal ou no Brasil foram mantidas conforme suas ortografias originais. 
espontânea" (Bourdieu et al., 1991: 35). Entre outros temas, sublinho que o papel da analogia neste processo é um dos tópicos especificamente tratados (Bourdieu et al., 1991: 49-52) e que é também possível observar, mesmo que neste caso implicitamente, uma "indemonstrável influência" da ideia popperiana de que o trabalho do cientista sempre começa com problemas e termina com problemas (Baranger, 2012: 74-76). Não somente uma constante vigilância reflexiva (uma vez que nossa condição de seres sociais nos faz, de modo simultâneo e inevitável, pesquisadores e pesquisados) como demais aspectos destas suas concepções preliminares permanecerão em sua maturidade, mesmo que com diferentes intensidades.

\subsection{Das classes sociais na Argélia ao espaço social como metaobjeto}

Para um entendimento apropriado acerca de como Bourdieu construía seus objetos de pesquisa, em particular a noção de espaço social que recorrentemente o guiará neste processo, é preciso retornar ao palco das suas primeiras investigações empíricas. Foi a partir da conjunção do que aprendeu na Argélia de meados do século passado, pesquisando a realidade subalterna da então colônia, com sua bagagem teórico-filosófica, que ele deu início tanto a sua empresa científica como a sua evolução como pesquisador. Wacquant (2006: 16) relembra que os estudos etnográficos de Bourdieu do início dos anos 60 revelam "a forma como as suas inovações conceituais foram guiadas pelas questões práticas da pesquisa de campo". Naquela conjuntura o país era submetido ao que Bourdieu (1979), inspirado em Weber, chamou de "cosmos capitalista". Em meio ao choque entre processos civilizatórios distintos no qual se apercebeu, ele procurou investigar de modo original dimensões íntimas da vida daquelas pessoas, suas condições objetivas de trabalho, as relações que aquela gente reproduzia ou (re)configurava entre economia e tempo, bem como as projeções de futuro dos trabalhadores argelinos.

Baranger (2012: 119-141) se propõe a mostrar o caminho por meio do qual foi sendo construído o objeto de pesquisa de A distinção (Bourdieu, 2007), fazendo um resgate a partir de Trabalho e trabalhadores na Argélia - e assim demonstrando que é dali que Bourdieu começa a evoluir da ideia de "classe" para a de "espaço social", a qual chegará na sua problematização em $A$ distinção e seguirá adiante. Foi na Argélia que Bourdieu elaborou critérios para a definição de classes naquela sociedade e, partindo deles, concebeu suas categorias. Sobre isso, "ainda que tendo presentes as categorias da sociologia clássica, tanto marxista como weberiana, Bourdieu seguiu gerando um esquema de classes sociais a partir dos dados", sendo também importante destacar: "o notável é como Bourdieu, antes de aplicar um esquema teórico pré-concebido, procede em um sentido indutivo para gerar suas categorias" (Baranger, 2012: 120-122, grifos meus). Ou seja, as classes sociais argelinas foram formuladas por meio de um procedimento que lhe permitiu reunir casos individuais em 
cada uma das categorias criadas. Mesmo considerando a sociologia clássica e as nomenclaturas francesas das categorias profissionais de 1954, "a definição das classes aparece como o resultado de um procedimento empírico que, praticamente por ensaio e erro, vai agrupando os entrevistados em categorias internamente homogêneas" (Baranger, 2012: 123, grifos meus).

Se já no início Bourdieu inovou ao construir classes a partir dos dados que gerava e analisava, nos anos seguintes avançou no sentido da construção de uma noção de espaço social multidimensional, ou seja, como uma "estrutura de estruturas" composta de campos, que permite deslocamentos e conversões de capitais entre campos. Baranger (2012: 123-131) recupera como se deu tal construção e como ela desembocou na atividade fundamental de sua composição científica. Construir um objeto ao seu modo passaria então pela elaboração do que Bourdieu chamou de "sistema de significações" como uma topologia ou espaço social "composto pela justaposição de campos, que será fundamental ao seu programa de investigação" (Baranger, 2012: 126). Sobre o que aponto ser seu metaobjeto - uma vez que este será o termo da metalinguagem teórica, criada e articulada por Bourdieu, que norteará a construção dos seus objetos empíricos após a sistematização do seu pensamento -, disse Bourdieu (1996: 27): "o que existe é um espaço social, um espaço de diferenças [...] o espaço social é a realidade primeira e última já que comanda até as representações que os agentes sociais podem ter dele."

Aos meus olhos, o que se evidencia aqui é esta atitude de construção de um metaobjeto denominado de espaço social. Tal atividade se dará tendo em vista a criação de um sistema coerente de relações, sendo deste modo geradora de linguagem própria sobre os fenômenos sociais.

\subsection{Lição da maturidade}

Quer seja em seu primeiro texto epistemológico (Bourdieu et al., 1991), na apresentação de um dos seus livros (Bourdieu, 2011: 26-44), num curso ministrado na maturidade (Bourdieu, 1989a), ou na entrevista na qual comentou seu primeiro trabalho epistemológico (Bourdieu, 1991: 248, 252-253), a construção do objeto é tema ao qual Bourdieu sempre atribuiu importância crucial. Para ele: "o que conta, na realidade, é a construção do objeto, a eficácia de um método de pensar nunca se manifesta tão bem como na sua capacidade de constituir objetos socialmente insignificantes em objetos científicos ou, o que é o mesmo, na sua capacidade de reconstruir cientificamente os grandes objetos socialmente importantes, apreendendo-os de um ângulo imprevisto" (Bourdieu, 1989a: 20, grifos meus) ${ }^{3}$.

Acredito que seja em sua maturidade, após a realização de uma série de estudos consagrados, que ele melhor consegue significar o lugar da construção

3 Todas as demais citações neste tópico, somente acompanhadas de número de página, são referentes a Bourdieu (1989a). 
do objeto em sua epistemologia. No âmbito de um seminário introdutório à sua sociologia reflexiva, Bourdieu discorreu sobre como se dava a construção do objeto em sua prática de pesquisa, tendo como objetivo oferecer direcionamentos para a audiência. A título ilustrativo, a seguir recupero dois dos princípios práticos então professados.

O primeiro, pensar o mundo em termos relacionais, é operacionalizado por meio da noção de campo enquanto modo de denominar sinteticamente e conduzir o processo de construção do objeto. Por meio desta noção, "torna-se presente o primeiro preceito do método, que impõe que se lute por todos os meios contra a inclinação primária para pensar o mundo social de uma maneira realista ou, para dizer como Cassirer, substancialista: é preciso pensar relacionalmente" (27). E como neste tipo de análise relacional não é "possível apreender os espaços sociais de outra forma que não seja a de distribuições de propriedades entre indivíduos" (29), Bourdieu sugere um instrumento metodológico para a construção do objeto por meio da comparação de características de um conjunto de agentes ou de instituições. Diante disso, é possível dizer que, para construir o objeto em termos bourdieusianos, é necessário criar ou recorrer a instrumentos que impulsionem e mesmo obriguem o pesquisador a "pensar relacionalmente". Tais recursos precisariam ser apropriados à análise relacional, tal qual o quadro que ele sugere (29), e deste modo possibilitariam a construção do espaço social.

A epistemologia de Bourdieu evolui no sentido de estabelecer relações entre posições e seus significados num campo ou espaço social, aqui entendido como metaobjeto recorrente nas pesquisas de sua fase mais madura. Neste sentido, outro elemento que terá papel crucial neste processo será o raciocínio por meio de analogias (32). Bourdieu usa e sugere a analogia como forma legítima de comparação e princípio de elaboração das relações entre as relações. Se voltarmos ao que foi professado em $O$ ofício, nos reencontraremos com o princípio da primazia das relações, agora elaborado com uma maior ênfase metodológica e indicações práticas, ou seja, numa linguagem menos professoral, com mais exemplos de boas práticas e soluções de problemas de pesquisa, enfim, mais próxima do que ele declarou que faria se tivesse de escrever novamente aquele primeiro livro (Bourdieu, 1991: 256).

O segundo princípio está relacionado à "ruptura", outro princípio de $O$ ofício que se mantém presente em sua maturidade 4 . Disse Bourdieu que, "construir um objecto científico é, antes de mais e sobretudo, romper com o senso comum, afinal, o pré-construído está por toda parte" (34), para ele, seria preciso atentar ao objeto pré-construído, realizar o salto epistemológico e se manter sujeito a ajustes a partir da postura reflexiva do pesquisador no curso da

4 Mesmo que com intensidade distinta, como pode ser visto em um dos últimos trabalhos que coordenou (Bourdieu, 2003). 
investigação. Dentro desta perspectiva, professa-se uma atitude de "vigilância epistêmica" que implica em "tomar para o objecto o trabalho social de construção do objeto pré-construído: é aí que está o verdadeiro ponto de ruptura" (28). Um caminho que ele apresenta para que o pesquisador possa superar tal barreira é investir no resgate e na elaboração da história social da emergência do problema e de sua constituição progressiva. Este seria um "instrumento poderoso" para reduzir os riscos de vir a se tornar "objecto dos problemas que toma como objecto" (37), justamente por propiciar o questionamento de pré-noções do senso comum e de sua área científica.

\section{Teoria como prática}

$\mathrm{Na}$ visão bourdieusiana, teoria tem um caráter indissociavelmente prático. Tal concepção lhe serviu para se posicionar antagonicamente aos adversários por ele apontados como adeptos do que chamava de "teoria teórica". Contra esta, o significado que Bourdieu (1989b: 59-60) atribui ao termo é prático e estratégico: "a teoria científica apresenta-se como um programa de percepção e de acção só revelado no trabalho empírico em que se realiza. [...] Tratar da teoria como um modus operandi que orienta e organiza praticamente a prática científica é, evidentemente, romper com a complacência um pouco feiticista que os 'teóricos' costumam ter para com ela."

Brubaker (1993: 213, grifos meus) opina sobre a concepção bourdieusiana de teoria do seguinte modo: "a eficácia prática de teoria, penso eu, é melhor capturada nos termos sociológicos sugeridos por Bourdieu. Como uma prática social como outras, a pesquisa social é dirigida e instruída por disposições internalizadas, não por proposições codificadas, pela lógica prática do habitus, não pela lógica teórica estabelecida em tratados e manuais". Aceito, como Brubaker (1993: 212), o convite do próprio Bourdieu para "tratar teoria como habitus" e compreender devidamente seu significado prático, seu valor de uso investigativo, ou seja, sua serventia ao que se quer estudar de modo reflexivo.

A partir disso, é também possível pensar teoria como conhecimento conjectural (Popper, 2006) de partida do qual um pesquisador se arma para enfrentar a investigação empírica. A teoria assim está condenada a somente funcionar como prática, a ser usada e fortalecida ou retocada, e até mesmo descartada, em decorrência desta.

Para avançar neste sentido preciso recuperar três pontos. O primeiro nos oferece conceitos heurísticos e abertos (Santoro, 2011) que, por exemplo, em texto de análise retrospectiva de sua principal obra, Bourdieu (1996) também chama de noções. Tais noções seriam instrumentos criados e propostos por ele para a prática da sua sociologia reflexiva, mas que, por inerente característica constitutiva, estão abertas a ressignificações a partir de novos usos. É a prática 
científica rigorosa que comanda seus significados, e não o contrário. Deste modo, fazer sociologia bourdieusiana é fazer aberto e bom uso de tais noções a partir dos desafios impostos pelos novos problemas que emergem e tomam a atenção e o interesse do pesquisador. Assim, definições tendem a não fazer muito sentido, uma vez que sempre estaremos lidando com usos circunstanciais dos termos, ou seja, partindo das regras do "jogo de linguagem" (Wittgenstein, 1999) no qual se dá cada uso.

O segundo ponto é encontrado na consideração de Robbins (2000: 25) sobre a posição bourdieusiana em relação ao significado de conceitos. Estes seriam instrumentos "por meio dos quais nós definimos e classificamos fenômenos. Eles não têm um significado intrínseco. Não representam coisas reais, mas adquirem realidade objetiva enquanto funcionam nos ajudando a dar sentido às coisas e objetos. Seus usos são transitórios. Eles nunca são destruídos, mas sempre são superados. Trazem em sua constituição uma obsolescência funcional". Bourdieu entendia o significado dos conceitos que usava não como designadores das "coisas do real", mas sim como uma realidade objetiva criada (Robbins, 2000: 35). Tal entendimento reforça o caráter contingente e conjectural da teoria neste modo de fazer sociologia necessariamente teórica e empírica.

O terceiro e último ponto recupero de Vandenberghe (1999: 21). As noções de campo (ou espaço social), capital (ou poder) e habitus (ou disposições) não podem ser definidas separadamente. De modo geral, tais noções precisam umas das outras para se sustentarem ou mesmo serem expostas de modo apropriado e "podem ser definidas, mas somente dentro do sistema teórico que constituem" (Bourdieu e Wacquant, 1992: 96); afinal, servem para o estudo de aspectos específicos dos fenômenos sociais tomados como objetos de pesquisa e reconstruídos como tais nos termos bourdieusianos.

\section{Uma interpretação a partir do segundo Wittgenstein}

Acredito que um modo apropriado de interpretar e fazer uso da prática teórica bourdieusiana é encará-la como uma linguagem que, em sua contingência como tal, sempre está sujeita a ressignificações decorrentes da construção e estudo de cada novo objeto. Ou seja, deste modo é possível pensar a sociologia bourdieusiana como uma linguagem originalmente elaborada por meio de um processo centrado no que ele denominava de "construção do objeto". Ao avançar neste sentido, Bourdieu significava sobre o que observava no cotidiano e (re)configurava como problema de pesquisa.

A fertilidade do seu legado está justamente no potencial criativo inerente ao modo como foram elaboradas suas convicções. Sua concepção de sociologia se oferta e, ao mesmo tempo, desafia a própria reconstrução crítica. Pensar com Bourdieu é também pensar contra ele (Wacquant, 1992); afinal, 
seu modus operandi autoriza a construção adaptativa-reflexiva a partir dele. Mais que isso, acredito que agir deste modo é ser o mais fiel possível ao seu legado. Com consciência do que gostaria de transmitir a partir dos seus trabalhos, ele recorre a uma bela alegoria musical para explicitar suas intenções neste sentido:

se é permitida esta analogia, diria que trabalhos científicos são parecidos com uma música que fosse feita não para ser mais ou menos passivamente escutada, ou mesmo executada, mas sim para fornecer princípios de composição. Compreender trabalhos científicos que, diferentemente dos textos teóricos, exigem não a contemplação mas a aplicação prática é fazer funcionar praticamente, a respeito de um objecto diferente, o modo de pensamento que nele se exprime, é reactivá-lo num novo acto de produção tão inventivo e original como o acto inicial. (Bourdieu, 1989b: 63-64, grifos meus)

A força do pensamento analógico na prática científica é reconhecida, utilizada e sublinhada repetidas vezes por Bourdieu. Foi este o modo que ele escolheu para insinuar que seu trabalho oferecia "princípios de composição" e não uma "ópera" pronta a ser executada repetidamente, mesmo que com perfeição. O desafio que nos deixou foi o de praticar seu modo de pensar, sua linguagem, recriando-o nos próximos atos de produção científica.

Foi com isso em mente que me dediquei à leitura do segundo Wittgenstein (W. II), mais especificamente, de suas Investigações filosóficas. Ele foi um dos filósofos dos quais Bourdieu mais se serviu. Perguntado porque o citava recorrentemente, respondeu do seguinte modo: "Wittgenstein é sem dúvida o filósofo que me tem sido mais útil em tempos difíceis. É uma espécie de salvador para tempos de grande dificuldade intelectual: quando se trata de questionar as coisas tão óbvias como 'obedecer a uma regra'. Ou quando você tenta dizer coisas tão simples (e, ao mesmo tempo, quase inefáveis) como praticar uma prática” (Bourdieu, 1990: 21-22).

Se Wittgenstein funcionava, nas palavras do próprio Bourdieu, como seu "salvador" em situações difíceis, gostaria de me nutrir da principal obra da fase madura deste filósofo para interpretar pragmaticamente o modus operandi bourdieusiano como uma linguagem. Para tal, avanço a partir da visão de Brubaker (1993). Se teoria e prática de pesquisa social bourdieusiana podem ser vistas como uma prática social como as demais, também podem ser interpretadas a partir dos termos que W. II utilizou para analisar radicalmente a linguagem cotidiana e ordinária. Entendo que tudo o que foi recuperado e colocado até aqui, direta ou indiretamente, são desdobramentos da linguagem criada por Bourdieu ao "pôr em jogo" seu modus operandi. Além disso, é justamente tal linguagem que o gerou, e que foi por meio dele gerada, que hoje nos é possível acessar do seu habitus científico. O que há de mais genuíno na sociologia bourdieusiana, seu modo de pensar-proceder, conceber-praticar, 
foi e é a linguagem elaborada a partir de outras (1.1), que evoluiu ao longo de sua prática investigativa e por meio desta ganhou novos termos (1.2), foi professada (1.3) e se consubstanciou em sua concepção-prática de teoria sociológica (2).

Em termos gerais, Investigações filosóficas (IF) é um livro no qual Wittgenstein (2009) se volta contra a lógica, incluindo aí seu Tractatus (2011), e o essencialismo filosófico. Para ele, a linguagem apresenta muito mais possibilidades que apenas a de designar coisas. É assim que propõe outra perspectiva na qual a linguagem será analisada de forma radical em seu uso. Tal uso que fazemos das palavras é tomado por W. II como ponto de partida e de reflexão por meio da análise de atuações em cenas do cotidiano social em sua condição de "jogo de linguagem". É esta ideia de jogo que estará no cerne de sua concepção radical (pragmática e descritiva do "em uso" linguístico).

A linguagem nesta perspectiva não é vista como estática, plenamente estruturada antes de tudo, mas sim como uma ação inerente ao pensar humano e a sua ação criativa. Além disso, ela também é concebida como condição de possibilidade para a própria constituição do conhecimento. Como disse W. II, “'o sentido da palavra é aquilo que a explicação do sentido explica'. Isto é: se queres compreender o uso da palavra 'sentido', procura aquilo que se chama 'explicação do sentido'” (IF 560). Nesta busca interpretativa se estará sempre lidando com usos circunstanciais dos termos, com as regras do jogo de linguagem particular no qual tais termos se inserem e com as explicações contingentes às quais, a partir deles, é possível chegar.

Apresentar explicações sobre palavras, e demais coisas que acontecem entre pessoas no mundo, envolve uma prática social de investigação que se dá por meio da elaboração de linguagem sobre este mundo. Se, por um lado, W. II acreditava que era na descrição minuciosa das interações cotidianas que poderíamos observar como, de modo geral, operamos a partir de interpretações tomadas como certas para gerar entendimento numa interação, por outro, Bourdieu se propunha a elaborar explicações rigorosas e empiricamente ancoradas sobre o que investigava e, consequentemente, apresentá-las nos mais diversos tipos de texto. Os termos que usava e consagrou em seu jargão foram criados neste processo e, ao mesmo tempo, criaram seus objetos, suas pesquisas e os resultados apresentados.

Bourdieu manipulou seus objetos por meio dos instrumentos de pensamento que ele próprio ressignificou e fez evoluir. Sua terminologia foi precisa o suficiente para dar coerência ao sistema teórico de termos-noções que orientou suas pesquisas, e ao mesmo tempo aberta para que ele pudesse enfatizá-los e usá-los de modos diferentes em razão dos seus interesses investigativos em questão. A seguir recupero um bom exemplo do modo como ele praticava uma sociologia atenta à linguagem, quando assim criava e jogava bem esclarecidamente seu próprio jogo: 
O essencial é que, ao serem percebidas por meio dessas categorias sociais de percepção, desses princípios de visão e de divisão, as diferenças nas práticas, nos bens possuídos, nas opiniões expressas tornam-se diferenças simbólicas e constituem uma verdadeira linguagem. As diferenças associadas a posições diferentes, isto é, os bens, as práticas e sobretudo as maneiras, funcionam, em cada sociedade, como as diferenças constitutivas de sistemas simbólicos, como o conjunto de fonemas de uma língua ou o conjunto de traços distintivos e separações diferenciais constitutivas de um sistema mítico, isto é, como signos distintivos. (Bourdieu, 1996: 22, grifos meus).

A partir de IF é possível observar a prática social e o modus operandi bourdieusiano como uma prática sociológica que se configura numa linguagem por ela criada e utilizada ao longo de e para tal prática. Se para W. II não nos é possível pensar sem linguagem, creio não ser possível fazer sociologia bourdieusiana sem a referência da linguagem criada por Bourdieu sobre o mundo. $\mathrm{Na}$ prática do pesquisador, a metalinguagem bourdieusiana se torna a forma de pensamento, os termos dos quais ele se serve para construir o seu particular objeto de pesquisa. É assim que pode vir a compor uma linguagem específica sobre o seu tema de estudo, a partir dos princípios de composição daquela metalinguagem inspiradora.

O que está no cerne desta interpretação é o status epistêmico do modus operandi, entendido quase que como o habitus metodológico do próprio Bourdieu. Seu significado não está fora da ação criativa-investigativa geradora de linguagem, cabendo ou não em maior ou menor grau àquela ação. Significa-se com e pela prática. Esta tem o primado epistemológico - isso é, o pragmatismo - e tal só se entende, inclusive no caso de Bourdieu, quando a linguagem, locus do conhecimento objetivo, também for tida como uma prática, justamente a tal ação criativa-investigativa. Mais especificamente, esta ação se configuraria em dois aspectos somente separáveis em termos analíticos: (1) na construção do objeto como prática linguística, uma vez que esta atividade é, como vimos, o cerne do modus operandi bourdieusiano e (2) na linguagem que se gerou por meio disso, ou seja, na sua teorização sociológica que visa oferecer noções-instrumentos a serem utilizados noutras investigações.

Em síntese, acredito que Bourdieu criou e praticou uma linguagem sobre o mundo social. São a riqueza e a abertura de tal criação que ultrapassam a contingência das opções teórico-epistemológicas que tomou na França do século passado e torna seu trabalho ainda tão inspirador.

Por fim, vale a pena registrar que não era apenas uma visão do mundo pragmática que o aproximava do autor de IF. Assim como Bourdieu, W. II também encontrou na música "imagens mentais" para pronunciar palavras e assim desafiar nossa imaginação. A sensibilidade necessária à devida escuta de um tema musical é comparada por ele ao entendimento de nossa linguagem: "compreender a frase da nossa linguagem está mais perto do que é compreender 
um tema em Música do que se pensa" (IF 527). Se, em sua própria analogia, Bourdieu registrou que um trabalho científico deve oferecer princípios de composição, acredito que seja na sutileza de uma alegoria como esta que podemos ser tocados por seu signo mais distintivo.

\section{Considerações finais sobre e para a prática do investigador social}

Muito embora o trabalho investigativo que se deu a partir desta interpretação não deva ser tomado como exemplar, ao interpretar o legado bourdieusiano deste modo me foi possível desenvolver uma tese na qual se procurou compor uma interpretação sociológica inspirada e nutrida pelo trabalho do sociólogo francês (Sá, 2015). Nela, é evidente a influência da referência original, a presença marcante daquele estilo. Ao mesmo tempo, a tese resultou de outro ato criador, orquestrado por instrumentos desenvolvidos sob medida para outro contexto investigativo.

Acredito que tal leitura da epistemologia de Bourdieu, a partir dos esclarecimentos do segundo Wittgenstein, pode ser também útil para outros investigadores interessados em fazer uso reflexivo e crítico desta abordagem sociológica, uma vez que seus conceitos-instrumentos podem ser vistos como uma linguagem objetiva criada e aberta para ressignificações. Direcionar o reconhecimento dos seus limites e possibilidades também neste sentido pode viabilizar tanto uma prática de pesquisa mais consciente, como levar cada pesquisador ao desafio de compor sua própria linguagem a partir do modus operandi de um autor como Pierre Bourdieu. O desafio da criação científica nestes termos é o de uma construção que se reporta à experiência de cada investigação. Neste sentido, o trabalho de Bourdieu oferece "princípios de composição".

\section{Referências}

BACHELARD, G. (1996 [1938]), A formação do espírito científico: contribuição para uma psicanálise do conhecimento. Rio de Janeiro: Contraponto.

BARANGER, D. (2012), Epistemología y metodología en la obra de Pierre Bourdieu. Posadas, $2^{a}$ edición ( $1^{\text {a }}$ electrónica).

BOURDIEU, P. (1979 [1963]), O desencantamento do mundo: estruturas econômicas e estruturas temporais. São Paulo: Perspectiva.

BOURDIEU, P. (1989a), "Introdução a uma sociologia reflexiva”, in Pierre Bourdieu, Poder simbólico. Portugal/Brasil: Difel/Bertrand: 17-58.

BOURDIEU, P. (1989b [1984]), “A gênese dos conceitos de habitus e campo”, in Pierre Bourdieu, Poder simbólico. Portugal/Brasil: Difel/Bertrand: 59-73.

BOURDIEU, P. (1990). "Fieldwork in Philosophy (Interview)", in Pierre Bourdieu, Other Words: Towards a Reflexive Sociology. Stanford: Stanford University Press: 3-33.

BOURDIEU, P. (1991), "Meanwhile, I have come to know all the diseases of sociological understanding" (An interview with Pierre Bourdieu, by Beate Krais), in Pierre Bourdieu et al., The Craft of Sociology: Epistemological Preliminaries. Berlin-New York: Walter de Gruyter. 
BOURDIEU, P. (1996 [1994]), "Espaço social e espaço simbólico", in Pierre Bourdieu Razões práticas: Sobre a teoria da ação. Campinas: Papirus: 13-33.

BOURDIEU, P. (org.) (2003 [1993]), A miséria do mundo. Petrópolis: Vozes.

BOURDIEU, P. (2007 [1979]), A distinção: crítica social do julgamento. São Paulo/Porto Alegre: Edusp/Editora Zouk.

BOURDIEU, P. (2011 [1984]), Homo Academicus. Florianópolis: Ed. da UFSC.

BOURDIEU, P. et al. (1991 [1968]), The Craft of Sociology: Epistemological Preliminaries. Berlin-New York: Walter de Gruyter.

BOURDIEU, P. \& WACQUANT, L. (1992), An Invitation to Reflexive Sociology. Chicago: The University of Chicago Press.

BRUBAKER, R. (1993), "Social theory as habitus", in Craig Calhoun et al. (org.), Bourdieu: Critical perspectives. Cambridge: Polity Press: 212-234.

POPPER, K. (2006 [1963]), Conjecturas e refutações: O desenvolvimento do conhecimento científico. Coimbra: Almedina.

ROBBINS, D. (2000), "The socio-genesis of the thinking instruments", in Derek Robbins, Bourdieu and culture. Londres: Sage: 25-41.

SÁ, M. (2015). Os filhos das feiras e o campo de negócios agreste. Tese de Doutoramento em Sociologia. Braga: Universidade do Minho. Disponível em: http://repositorium.sdum.uminho.pt/handle/1822/35680. Acesso em: 24/07/2015.

SANTORO, M. (2011), "From Bourdieu to cultural sociology". Cultural Sociology, 5(1): 3-23.

VANDENBERGHE, F. (1999), “'The real is relational': an epistemological analysis of Pierre Bourdieu's generative structuralism”, Sociological Theory, 17 (1): 32-67 [as páginas indicadas nas citações são referentes à tradução de Gabriel Peters, sem data, disponível em: https:// www.academia.edu/859739/O_Real_e_relacional_uma_analise_epistemologica_do_estruturalismo_gerativo_de_Pierre_Bourdieu. Acesso em: 12.09.14].

WACQUANT, L. (1992), "Preface", in Pierre Bourdieu; Loïc Wacquant (orgs.), An Invitation to Reflexive Sociology. Chicago: The University of Chicago Press: ix-xiv.

WACQUANT, L. (2006), "Seguindo Bourdieu no campo", Revista Sociologia e Política, Curitiba, 26: 13-29.

WITTGENSTEIN, L. (1999 [1953]), Investigações filosóficas. São Paulo: Editora Nova Cultural. WITTGENSTEIN, L. (2011), Tratado lógico-filosófico e Investigações filosóficas, 5. a ed. Lisboa: Fundação Calouste Gulbenkian. 